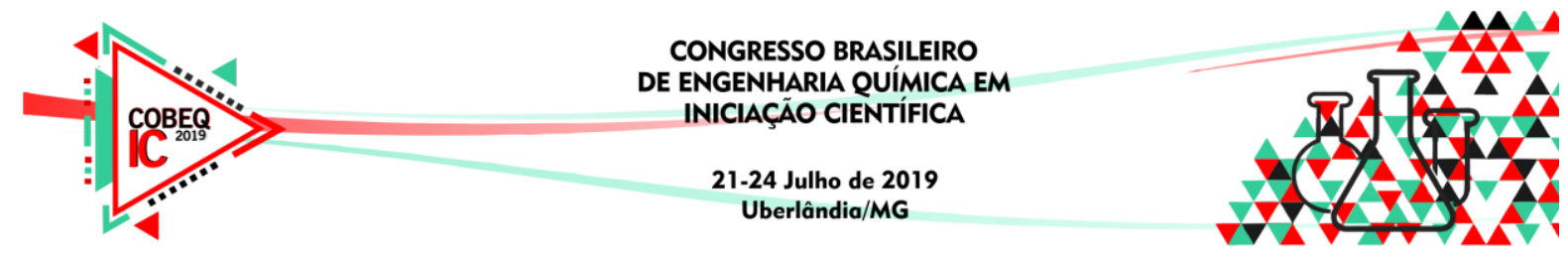

\title{
ANÁliSE DOS CUSTOS DE PRODUÇÃO DE LIPASES PRODUZIDAS POR FERMENTAÇÃO EM ESTADO SÓLIDO EM UM BIORREATOR DE BANDEJAS
}

\author{
E. X. RAMALHO ${ }^{1}$, P. H. B. FERNANDES ${ }^{1}$, C. O. AVILA ${ }^{2}$, R. S. DUTRA ${ }^{3}$ \\ e L. M. GRAJALES ${ }^{1,3}$ \\ ${ }^{1}$ Universidade Federal do Tocantins, Curso de Engenharia de Alimentos \\ ${ }^{2}$ Universidade Federal do Tocantins, Programa de Pós-Graduação em Desenvolvimento \\ Regional \\ 3 Universidade Federal do Tocantins, Programa de Pós-Graduação em Agroenergia \\ E-mail para contato: grajales@uft.edu.br
}

\begin{abstract}
RESUMO - Este estudo visa analisar os custos de produção de lipases extracelulares do fungo Metahirzium anisopliae utilizando bagaço do coco babaçu como substrato produzidas em um biorreator de bandejas. Para tanto, foram produzidas lipases por Fermentação em Estado Sólido em escala de laboratório e, com os dados coletados, estimou-se a produção mensal de lipases em escala de reatores para um biorreator de bandejas. As fermentações foram conduzidas em frascos erlenmeyers com $10 \mathrm{~g}$ de meio de cultura, a $28^{\circ} \mathrm{C}$ durante 7 dias. A atividade enzimática foi determinada por método titulométrico, sendo a média de $28,06 \mathrm{U} / \mathrm{mL} \pm 4,15 \mathrm{U} / \mathrm{mL}$. A partir da produção mensal estimada foi feita uma análise de custos baseada na teoria dos preços de Milton Friedman. Foram calculados os custos fixos, custos variáveis, custos totais, custo fixo médio, custo variável médio, custo total médio, custo marginal e custo de produção total envolvidos no processo. Os resultados mostraram que sob as condições de operação analisadas, o custo unitário de produção de extrato de lipases é de $\mathrm{R} \$ 261,76$ para unidades de $500 \mathrm{~mL}$. Comercialmente, o preço dos extratos enzimáticos de lipases é de $\mathrm{R} \$ 786,20 / 500 \mathrm{~mL}$. A tecnologia utilizada para a produção das lipases se mostrou promissora, já que o custo de produção ainda tem margem para cobrir os demais custos não levados em consideração neste estudo e a possibilidade de obtenção de lucros, sendo necessário realizar uma análise de mercado que permita obter o preço real de concorrência.
\end{abstract}

\section{INTRODUÇÃO}

As lipases são enzimas que catalisam a hidrólise de ésteres constituídos por glicerol e ácidos graxos de cadeia longa. Essa classe de enzimas é de grande importância biotecnológica, constituindo o principal grupo de catalizadores aplicados (JAEGER e EGGERT, 2002). De forma geral, estas podem ser encontradas amplamente na natureza, mas somente as lipases microbianas são comercialmente significativas, devido ao grande número de atividades catalíticas disponíveis, ao alto rendimento apresentado, à facilidade de manipulação genética e ao rápido crescimento dos micro-organismos em meios baratos, além 


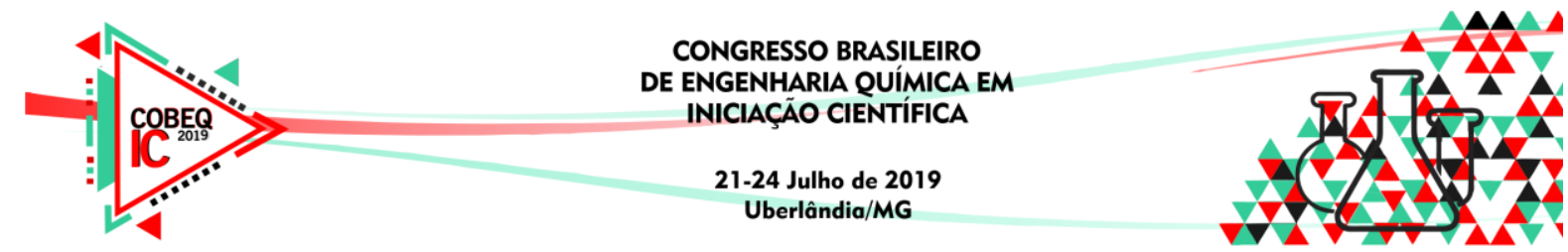

de serem mais estáveis do que as enzimas vegetais e animais, o que torna sua produção mais conveniente e segura (SHARMA et al., 2001; HASAN et al., 2006; COLLA, 2016).

Devido a esses fatores as lipases de origem microbiana vêm recebendo cada vez mais a atenção dos pesquisadores da área e empresários do setor industrial, constituindo o terceiro maior grupo de vendas de enzimas no mundo, ficando atrás somente das proteases e carboidrases (HASAN et al., 2006; MESSIAS et al., 2011). Entretanto o seu alto valor faz com que sua aplicação biotecnológica na indústria ainda seja bastante reduzida. Uma forma de reduzir os custos de produção é através de processos de Fermentação em Estado Sólido (FES), onde os micro-organismos se desenvolvem em um substrato orgânico sólido, para o qual resíduos agroindustriais podem ser utilizados com este fim (FERNANDES, 2007).

Nos últimos anos, em uma reserva extrativista localizada no município Xambioá, norte do estado do Tocantins, foram geradas mais de 6 toneladas de óleo de babaçu em virtude do processamento de 12,5 toneladas de amêndoa por ano. A matéria orgânica na forma de resíduo após esse processamento pode ser utilizada como fonte de nutrientes e energia para o desenvolvimento de micro-organismos (DUARTE, 2017). Alguns micro-organismos podem se adaptar facilmente a esses resíduos, tal é o caso do fungo filamentoso Metarhizium anisopliae, utilizado atualmente como controle biológico de pragas em diversos cultivos do Brasil (SENE et al., 2010). O grupo de pesquisa em engenharia de Biorreatores da Universidade Federal do Tocantins vem realizando análises de adaptação deste fungo a vários substratos e tem descoberto que é bom produtor de lipases (DUARTE, 2017).

Nesse contexto, o presente trabalho visa analisar os custos de produção de lipases extracelulares do fungo Metahirzium anisopliae utilizando bagaço do coco babaçu como substrato estimando a produção em um biorreator de bandejas.

\section{METODOLOGIA}

\subsection{Produção de Lipases por FES e extração}

Pré-inóculo e suspensão de conídios: O fungo entomopatogênico Metarhizium anisopliae (ICBC 425) foi repicado em frascos erlenmeyers contendo meio de cultura BDA, em ambiente estéril e incubado durante 07 dias a $28^{\circ} \mathrm{C}$. Após, uma solução nutriente aquosa constituída por $\mathrm{KCl}(0,065 \%)$, extrato de levedura $(0,033 \%)$ e tensoativo Tween $80 ®$ a $0,1 \%$ foi preparada, esterilizada e utilizada na preparação da suspensão de conídios. A concentração de conídios foi fixada em $2 \cdot 10^{7}$ conídios $/ \mathrm{mL}$.

Preparo dos substratos e fermentação em escala de frascos: O bagaço do coco babaçu utilizado como substrato foi fornecido pela cooperativa COOMESOL (Xambioá-TO). $10 \mathrm{~g}$ de substrato foram adicionados a frascos erlenmeyers e esterilizados. Após o substrato atingir a temperatura ambiente, em ambiente estéril, foi adicionado $1 \mathrm{~mL}$ da solução inoculante e $1 \mathrm{~mL}$ de azeite de oliva como indutor (FERNANDES, 2007; OLIVEIRA, 2013). O sistema foi mantido a $28{ }^{\circ} \mathrm{C}$ durante 7 dias. Foram realizadas seis repetições.

Extração da enzima: Adicionou-se uma solução extratora $(20 \mathrm{~mL}$ de tampão Mcllvaine pH 7,0 e $0,25 \%$ de tensoativo Tween 80 ) aos frascos contendo o substrato fermentado e 


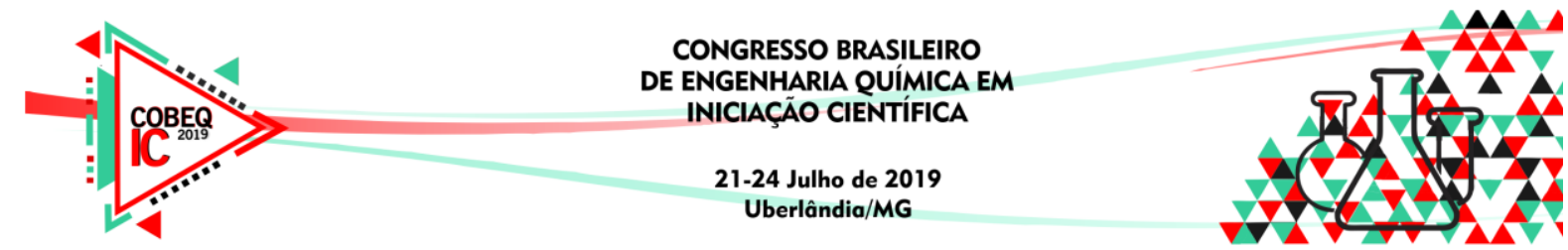

agitou-se manualmente até ficarem aparentemente homogêneos. O sistema foi filtrado, sendo coletado o extrato enzimático bruto para posterior determinação da atividade enzimática.

Determinação da atividade lipolítica enzima: Para cada repetição, foram preparados 19 $\mathrm{mL}$ de uma emulsão de triton X-100 (1\%), azeite de oliva (5\%) e tampão Mcllvaine pH 7,0 (94\%). Tal mistura foi agitada em um shaker durante 3 minutos a $37{ }^{\circ} \mathrm{C}$ e $200 \mathrm{rpm}$. Em seguida, foi adicionado $1 \mathrm{~mL}$ do extrato enzimático bruto à emulsão e esta foi colocada novamente em agitação por 30 minutos a $28^{\circ} \mathrm{C}$ e $200 \mathrm{rpm}$. A reação foi paralisada com 20 $\mathrm{mL}$ de solução de acetona:etanol 1:1 (v/v) e temperatura de $-4{ }^{\circ} \mathrm{C}$. Por fim, titulou-se com solução de $\mathrm{NaOH}$ 0,1 $\mathrm{M}$ até atingir $\mathrm{pH}$ final 11. A atividade enzimática (AE) foi definida pela Equação (1).

$$
\mathrm{AE}=\frac{\left(V_{t f}-V_{t i}\right) \cdot 1000 \cdot F d \cdot M}{t}
$$

Onde $V_{t f}$ é o volume de $\mathrm{NaOH}$ após 30 min de reação em mL; $V_{t i}$ é o volume de $\mathrm{NaOH}$ usado para titular o branco em $\mathrm{mL} ; F d$ é o fator de diluição; $M$ é a concentração molar de $\mathrm{NaOH}$ e $t$ é o tempo total de reação em minutos. A AE corresponde à quantidade de enzima que libera $1 \mu \mathrm{mol}$ de ácido graxo por minuto de reação a $28^{\circ} \mathrm{C}$ e $\mathrm{pH} 7,0$.

\subsection{Análise de Custos}

Estimativas de produção em escala de reatores: A partir da produção de lipases em escala de frascos foram feitas as estimativas para a produção em escala de reatores. $\mathrm{O}$ reator tomado como base para a realização da análise de custos de produção foi o fermentador de bandejas, desenvolvido pelo Grupo de Pesquisa em Engenharia de Biorreatores da Universidade Federal do Tocantins (UFT). Com o tamanho das bandejas do biorreator e a densidade bulk do resíduo do coco babaçu foi possível calcular a quantidade máxima de substrato que seria possível fermentar por mês. A partir dessa informação foram estabelecidas as quantidades de matérias primas necessárias para a produção no biorreator, considerando as mesmas proporções de materiais utilizados na produção em escala de frascos.

Determinação de custos: A teoria dos preços de Milton Friedman foi aplicada, para isto foi determinado o custo total do processo produtivo como o somatório dos custos fixos (equipamentos, salário dos funcionários e aluguel do imóvel) e dos custos variáveis (matérias primas, insumos, água e energia).

Cotação de matérias primas, insumos, equipamentos, vidrarias e utensílios: As estimativas de precificação das matérias primas, insumos, equipamentos, vidrarias e utensílios tiveram como base os preços praticados por sites de comércio eletrônico. As matérias-primas do processo são ágar batata dextrose (BDA), bagaço do coco babaçu, Tween 80, ácido cítrico, fosfato de sódio, azeite de oliva, cloreto de potássio, extrato de levedura, triton X-100, hidróxido de sódio e acetona. E como demais insumos têm-se etanol, GLP e lenha. Para os equipamentos, foi considerado um financiamento de 5 anos com juros de $2 \%$ ao mês. Isso visando viabilizar a sua aquisição e utilização na produção das lipases, uma vez que esses equipamentos apresentam valores de investimento bastante elevados para quem pretende iniciar um empreendimento. 


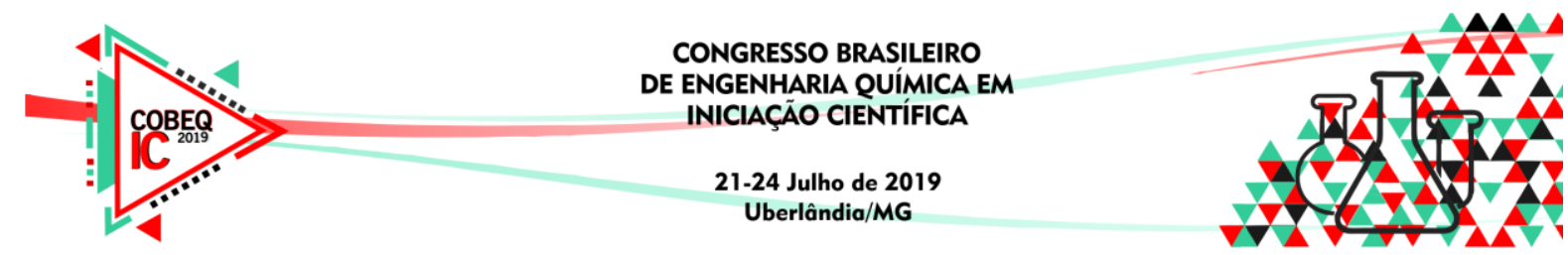

Cotação de aluguel, consumo de água e energia e mão de obra: O aluguel foi estimado com base na área total ocupada pelo Laboratório de Operações Unitárias da UFT, local onde se encontram os equipamentos para a produção das lipases. Para precificar o consumo de água e energia foram utilizadas as tarifas para setor industrial praticadas pelas concessionárias desses serviços no município de Palmas-TO, BRK Ambiental e Energisa, respectivamente. O custo da mão de obra foi estimado em cima da contratação de um biólogo como responsável técnico e um encarregado de serviços gerais.

\section{RESULTADOS E DISCUSSÃO}

\subsection{Produção de Lipases em Escala de Frascos}

A variável de resposta para a produção de lipases foi a Atividade Enzimática, cuja média foi de $28,06 \mathrm{U} / \mathrm{mL} \pm 4,15 \mathrm{U} / \mathrm{mL}$. Estes resultados foram maiores do que as reportadas na literatura para sistemas similares, evidenciando que a aplicação do resíduo do coco babaçu para obtenção de enzimas lipolíticas, produto de altíssimo valor agregado, é bastante promissora (DUARTE, 2017; SENE et al., 2010). A alta atividade enzimática encontrada também está relacionada à adição de azeite de oliva como indutor no processo. Ele é um dos indutores mais utilizados nesse tipo de processo devido a sua composição rica em trioleína, composto ideal para a produção de vários tipos de lipases (FERNANDES, 2007; OLIVEIRA, 2013). Apesar do azeite de oliva ser um substrato caro, para este caso ele é usado em mínimas quantidades e resulta evidente o aumento na $\mathrm{AE}$, além disso, considerando o alto custo desse tipo de enzimas, vale a pena sua utilização no processo.

\subsection{Produção de Lipases Estimada para o Biorreator de Bandejas}

O biorreator de bandejas possui suporte para quatro bandejas com capacidade de acomodação de $800 \mathrm{~g}$ de bagaço de coco babaçu cada uma, possuindo assim capacidade máxima de fermentar $3200 \mathrm{~g}$ de substrato por batelada. Como a fermentação ocorre durante um período de 7 dias e toma um dia para preparar o material e mais um dia descarga e esterilização, somente é possível a realização de 3 bateladas por mês, sendo possível então fermentar mensalmente $9600 \mathrm{~g}$ de substrato.

Esse processo de produção possui rendimento de cerca de $2 \mathrm{~mL}$ de extrato enzimático para cada grama de substrato, portanto durante o mês seriam produzidos cerca de $19200 \mathrm{~mL}$ do extrato. Para esse estudo foi considerado que a apresentação de venda do extrato enzimático será de $500 \mathrm{~mL}$ gerando 38 produtos ao mês e 456 ao ano.

Sugere-se verificar em estudos futuros a possibilidade de imobilização das lipases, realizando testes de operacionalidade garantindo sua recuperação e utilização durante vários ciclos mantendo intacta sua atividade catalítica.

\subsection{Investimentos e Custos de Produção}

Matérias primas, insumos, equipamentos, vidrarias e utensílios: A fase de compras é uma das mais importantes da gestão de estoque, pois é a partir dela que são definidos os volumes iniciais, de modo que a quantidade inicial supra as necessidades de produção e possa 


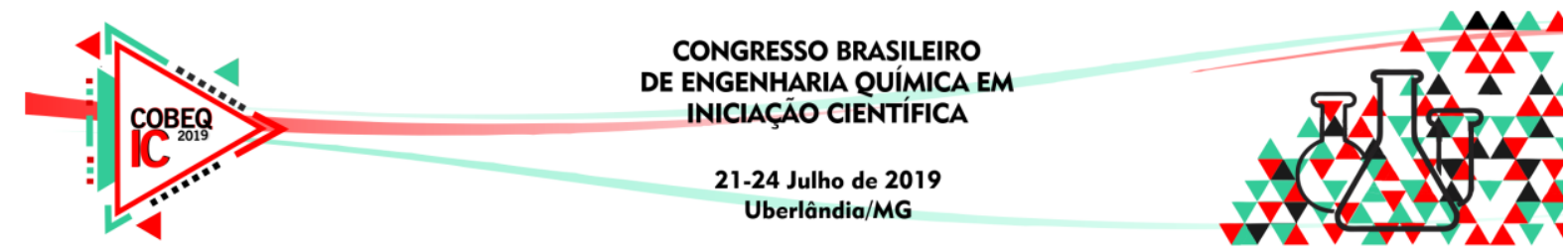

manter uma quantidade reserva, para eventuais imprevistos. Levando esses princípios em consideração, é necessário um investimento inicial de $\mathrm{R} \$ 1045,01 \mathrm{em}$ matérias primas. O baixo preço do bagaço do coco babaçu é o que mais contribui para que esse valor não fosse tão elevado, pois o mesmo é a principal matéria prima. $\mathrm{O}$ investimento inicial para os demais insumos foi estimado em $\mathrm{R} \$ 249,45$. Nos meses seguintes, para um ano, o gasto mensal com matéria-prima e insumos será de $\mathrm{R} \$ 100,00$ a $\mathrm{R} \$ 150,00$. O investimento em vidrarias e utensílios, que são bens duráveis, deve ser de R $\$ 1124,45$. O investimento em equipamentos, que também são bens duráveis, deve ser de $\mathrm{R} \$$ 83279,28, além do custo de manutenção periódica. Como este é o investimento mais elevado considerou-se a realização de um financiamento visando viabilizar a abertura do negócio. Considerando a taxa de $2 \%$ a.m. e um período de 60 meses, o investimento inicial em equipamentos passa a ser de R $\$ 2395,78 /$ mês. Dessa forma, será pago R \$143746,53, o que representa 142\% do vapor dos equipamentos.

Aluguel, consumo de água e energia e mão de obra: Considerado que o aluguel no setor industrial de Palmas-TO é em torno de $\mathrm{R} \$ 9,00 / \mathrm{m}^{2}$ e a área ocupada pelo laboratório de 58,55 $\mathrm{m}^{2}$, o valor do aluguel do imóvel é de $\mathrm{R} \$ 526,95$. O custo mensal do consumo de energia elétrica foi estimado em $\mathrm{R} \$ 1089,50$, sendo que $98 \%$ desse valor é referente ao banho ultratermostatizado e à incubadora BOD, e o de água, em R \$192,49. O custo mensal da mão de obra, considerando salários e encargos sociais e trabalhistas, é de R \$5504,94.

Custo de produção: De acordo com os valores supracitados, os custos para o primeiro mês de produção somam $\mathrm{R} \$ 12128,54$. Como são produzidos 38 produtos por mês, o custo inicial, por unidade, é de $\mathrm{R} \$ 319,17$. Todavia, para definir o custo por unidade, será levado em consideração os custos de produção anual. Os custos com mão de obra, aluguel, consumos de água e energia elétrica, bem como com o financiamento dos equipamentos, são praticamente constantes por mês, sendo assim, estimados proporcionalmente para um ano. Entretanto, como as matérias primas e insumos são mantidos em estoque, o custo mensal varia com o seu consumo e a necessidade de reposição. Além disso foi considerado o investimento com vidrarias e demais utensílios. Levando isso em consideração, foi estimado o custo de produção para o primeiro ano em torno de $\mathrm{R} \$ 119362,39$. Como são produzidos 456 produtos por mês, têm-se que o custo, por unidade, é de $\mathrm{R} \$ 261,76$.

\subsection{Análise de Mercado}

O preço comercial de extratos enzimáticos é de aproximadamente $\mathrm{R} \$ 780,00$ para cada $500 \mathrm{~mL}$, gerando um lucro estimado em mais de 60\%. Dessa forma, a tecnologia utilizada para a produção das enzimas lipolíticas se mostra promissora, já que a estimativa de lucro ainda tem margem para cobrir os custos que não foram levados em consideração neste estudo.

Para determinar definitivamente o quão lucrativo é o processo estudado é necessário realizar uma análise mais profunda que permita obter o preço real de concorrência e que inclua a modelagem e maximização de preços, a demanda através de enquetes especializadas, o equilíbrio de mercado e posteriormente, análise de mercado. Adicionalmente, a estudar a participação no mercado nacional e internacional. 


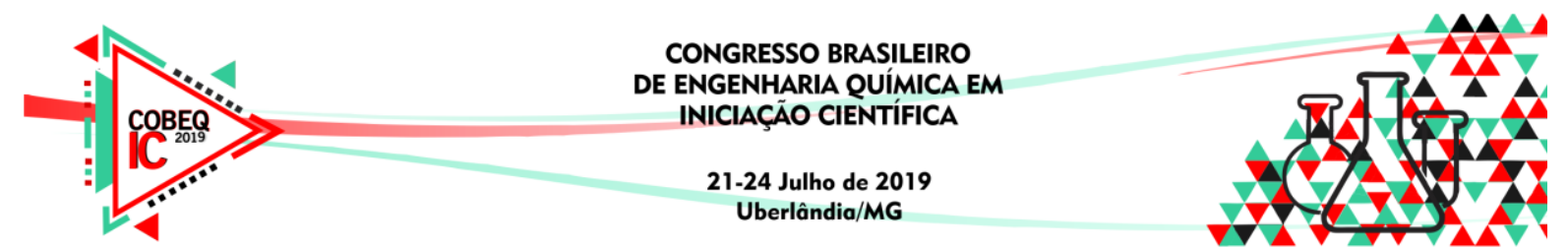

\section{CONSIDERAÇÕES FINAIS}

Os valores de atividade enzimática obtidos a partir da fermentação em escala de frascos evidenciam que o bagaço do coco babaçu é uma boa fonte de nutrientes e energia para o desenvolvimento do fungo $M$. anisopliae, portanto, é um substrato promissor para a síntese de enzimas lipolíticas, um produto de alto valor agregado.

A avaliação de custos realizada mostrou a possibilidade de obtenção de lucro de mais de $60 \%$ de lucro extrapolando o processo produtivo para a escala de um biorreator.

\section{REFERÊNCIAS}

COLLA, L. M.; REINEHR, C. O; COSTA, A. V. Aplicações e produção de lipases microbianas. Rev. CIATEC - UPF, vol.4 (2), p.p.1-14, 2012.

DUARTE, L. M. Produção de enzimas lipolíticas por fermentação em estado sólido a partir do fungo Metarhizium anisopliae utilizando bagaço do coco babaçu e arroz tipo I como substratos. TCC (Graduação) - Curso de Engenharia de Alimentos, Universidade Federal do Tocantins, Palmas, 2017.

FERNANDES, M. L. M. Produção de lipases por fermentação no estado sólido e sua utilização em biocatálise. Tese (Doutorado) - Curso de Química, Universidade Federal do Paraná, Curitiba, 2007.

HASAN, F.; SHAH, A. A.; HAMEED, A. Industrial applications of microbial lipases. Enzyme And Microbial Technology, Elsevier BV, v. 39, n. 2, p.235-251, 2006.

JAEGER, K.; EGGERT, T. Lipases for biotechnology. Current Opinion In Biotecnology, Elsevier BV, v. 13, n. 4, p.390-397, 2002.

MESSIAS, J. M.; COSTA, B. Z.; LIMA, V. M. G.; GIESE, E. C.; DEKKER, R. F. H.; BARBOSA, A. M. Lipases microbianas: Produção, propriedades e aplicações biotecnológicas. Semina: Ciências Exatas e Tecnológicas, Universidade Estadual de Londrina, [s.1.], v. 32, n. 2, p.213-234, 2011.

OLIVEIRA, A. C. D.; VARGAS, J. V. C.; RODRIGUES, M. L. F.; MARIANO, A. B. Utilização de resíduos da agroindústria para a produção de enzimas lipolíticas por fermentação submersa. Rev. Br. de Prod. Agroin., Campina Grande, v.15, n.1, p.19-26, 2013.

SENE, L.; ALVES, L. F. A.; LOBRIGATTE, M. F. P.; THOMAZON, D. Produção de conídios de Metarhizium anisopliae em meio sólido à base de resíduos agroindustriais. Arq. Inst. Biol., São Paulo, v. 77, n. 3, p.449-456, 2010.

SHARMA, R.; CHISTI, Y.; BANERJEE, U. C. Production, purification, characterization, and applications of lipases. Biotechnology Advances, Elsevier BV, v. 19, n. 8, p.627-662, 2001. 